\title{
A Comparative Analysis of Linear and Nonlinear Semi-Active Suspension System
}

\author{
IFTIKHAR AHMAD*†, AND AFZAL KHAN* \\ RECEIVED ON 01.02.2016 ACCEPTED ON 29.05.2017
}

\begin{abstract}
The ride quality including comfort and safety is the primary factor that is targeted in the design of an effective suspension system. The parametric behavior of suspension system is non-linear but for simplicity most of the researchers have assumed it as linear. The emphasis of this study is to analyze the non-linear behavior of basic components of the suspension system. Anon-linear mathematical model for semi-active suspension system equipped with MR (Magnetorheological) damper is developed based on a two degrees of freedom quarter vehicle model. Matlab/Simulink is used for simulation of the proposed model for different types of road disturbances. Transient response characteristics of the proposed non-linear model is compared with linear semi-active suspension model which show the difference between the responses of these models.
\end{abstract}

Key Words: Semi-Active Suspension System, Magnetorheological Damper, Transient Response, Matlab/Simulink.

\section{INTRODUCTION}

$\mathrm{T}$ suspension system in an automobile plays an important role in providing ride comfort and ride safety to the passengers. The ride comfort is mainly associated with the vertical vibrations transmitted as a result of the road irregularities whereas the ride safety is associated with the contact of the tires with the road. The suspension system is the only mechanism which separates the vehicle body from the tires Roa et. al. [1]. That is why the automobile companies and design engineers are paying much attention to the best design of the suspension systems. The elements of the suspension system provide ride comfort by absorbing the vibrations produced in the vehicle body. These excessive vibrations in the vehicle have many drawbacks such as reduced vehicle-frame life, negative biological effects on the passengers and harmful consequences to the cargo [2].

The vehicles suspension systems are of three types, passive, semi-active and active suspension systems. The traditional passive suspension system consists of a damper which is an energy dissipating element and a spring which is an energy storing element. These elements do not add energy to the system and that is why it is called a passive system, Khajavi and Abdollahi [3], Comparison between Optimized Passive Vehicle suspension system and semi active fuzzy logic controlled suspension system regarding ride and handling. 
The ride comfort needs spring having low stiffness value while ride safety needs spring having high stiffness value. So these two conflicting requirements led to the development of semi-active and active suspension systems. Unlike passive suspension system which have fixed damping coefficient, active and semiactive suspension system consists of variable dampers. In semi-active suspension system, the direction of the damping force depends upon the relative velocity across the damper where as its magnitude is adjustable, Carter [4]. In active suspension system, an actuator is placed parallel to the vehicle's body which moves the vehicle body in the suspension space to absorb the vibrations produced, Pekgokgoz et. al. [5].The major disadvantage of active suspension system is its high cost and huge external power. That is why automobile companies paying much attention to the development of semi-active suspension systems.

All the real world systems exhibit nonlinear behavior. The semi-active suspension system behaves linearly for low vibrations but exhibits nonlinear behavior for high vibrations. Most of the designer considered the semiactive suspension system as linear system. Very few researchers paid attention to its nonlinear behavior. Sawant et. al. [6] compared the vehicle dynamic system with nonlinear parameters subjected to actual road excitations. Non-linearities is considered only in spring, mass and damper of the passive suspension system and studied their behavior for individual and relative significance. Lajqi and Pehan [7] introduced a procedure for designing and optimizing nonlinear active and semiactive suspension systems. Hingane et. al. [8] presented the analysis of semi-active suspension system with Bingham model for MR damper for different road excitation. The comparison between passive and controlled semi-active suspension system showed the improvement of semi-active suspension system over passive.

Qazi et. al. [9] performed the modeling of passive and semi-active suspension system equipped with different control strategies. A comparison of semi-active suspension system for different control strategies is made with passive suspension system. The optimized fuzzy logic based semi-active suspension system improves the ride comfort by minimizing percentage overshoot and stabilizing time. Diala and Ezeh [10] studied the vibration transmissibility of a viscously damped isolator for a single and two degree of freedom suspension system. Non-linear viscous cubic damping is considered for the damper.

The rheological structure for an MR damper was described by the Sapinski and Filus [11]. The simplest parameter model of the MR damper used in this research is the non-linear Bingham plasticity model shown in Fig. 1. Kong et. al. [12].

$\mathrm{f}_{\mathrm{mr}}$ is the variable damping element which is placed parallel to the damper, co. The damping force for damper piston having some velocity $\dot{x}$, is given by Equation (1).

$$
f_{d}=f_{m r}(\dot{x})+C_{p 0} \dot{x}+f_{0}
$$

$\mathrm{x}$ is the displacement of the piston, $\mathrm{C}_{\mathrm{p} 0}$ is the hysteretic damp coefficient after MR fluid yield and $\mathrm{f}_{0}$ is the force of the accumulator.

Researchers have developed different non-linear models of the semi-active suspension system. The non-linearity is considered in one or more of the basic components of the semi-active suspension system to study its effect on the performance of the system. Chavan et. al. [13] considered non-linearities in all passive elements of the suspension system. Dial and Ezeh [10] considered a cubic

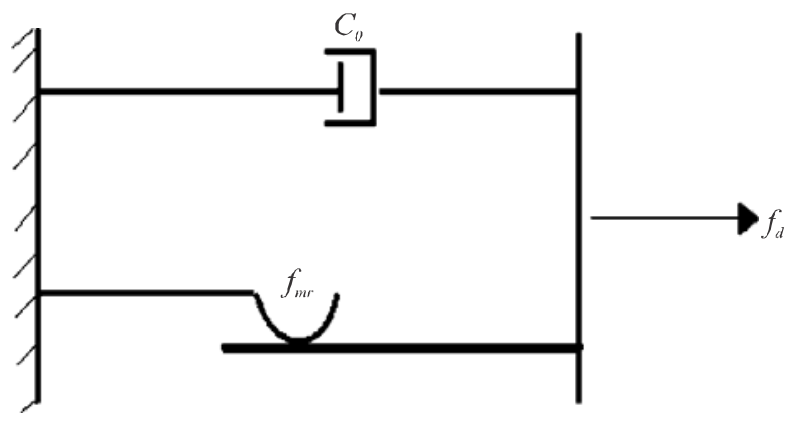

FIG. 1. RHEOLOGICAL STRUCTURE OF AN MR DAMPER FOR BINGHAM MODEL 
non-linear model only for the vibration isolator of a semiactive suspension system.

In this study non-linearities of all the passive elements such as tire spring, suspension spring and suspension damper as well as MR damper are taken into account.

\section{MATHEMATICAL MODELING}

A two degrees of freedom semi-active quarter car model is shown in Fig. 2. It consists of sprung mass, $M_{s}$ which is connected to the unsprung mass, $M_{u}$ through semi-active suspension system. The semi-active suspension system consists of spring stiffness $\mathrm{K}_{\mathrm{s}}$, suspension damper $\mathrm{C}_{\mathrm{s}}$ and a MR damper placed between sprung mass and unsprung mass. The tire stiffness is represented by $K_{t}$ while tire damping is neglected because of its minimum effect on final results. $\mathrm{x}_{\mathrm{s}}, \mathrm{x}_{\mathrm{u}}$ and $\mathrm{x}_{\mathrm{t}}$ are the sprung mass, unsprung mass and tire vertical displacement respectively. This quarter car model revels the basic properties of full vehicle model.

$f_{m r}$ is the controllable damping force generated by MR damper. The non-linear behavior of MR damper has been described by the Bingham plasticity model Kong et. al. [12].

The Equations (2-3) of motion for the designed quarter car model with two degrees of freedom are given as:

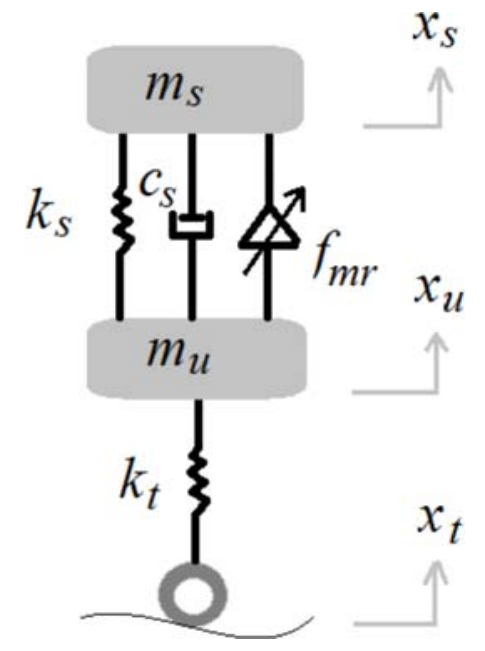

FIG. 2. SEMI-ACTIVE SUSPENSION SYSTEM

$$
\begin{aligned}
& m_{s} \ddot{x}_{s}+k_{s 1}\left(x_{s}-x_{u}\right)+k_{s 2}\left(x_{s}-x_{u}\right)^{2}+k_{s 3}\left(x_{s}-x_{u}\right)^{3}+ \\
& C_{s 1}\left(\dot{x}_{s}-\dot{x}_{u}\right)+C_{s 2}\left(\dot{x}_{s}-\dot{x}_{u}\right)^{2}+f_{d}=0 \\
& m_{u} \ddot{x}_{u}+k_{t 1}\left(x_{u}-x_{t}\right)+k_{t 2}\left(x_{u}-x_{t}\right)^{2}+k_{t 3}\left(x_{u}-x_{t}\right)^{3}-k_{s 1}\left(x_{s}-x_{u}\right)+ \\
& k_{s 2}\left(x_{s}-x_{u}\right)^{2}-k_{s 3}\left(x_{s}-x_{u}\right)^{3}-C_{s 1}\left(\dot{x}_{s}-\dot{x}_{u}\right)-C_{s 2}\left(\dot{x}_{s}-\dot{x}_{u}\right)^{2}-f_{d}=0
\end{aligned}
$$

$\mathrm{k}_{\mathrm{s} 1}, \mathrm{k}_{\mathrm{s} 2}$ and $\mathrm{k}_{\mathrm{s} 3}$ are suspension stiffness coefficients, $\mathrm{k}_{\mathrm{t} 1}, \mathrm{k}_{\mathrm{t} 2}$ and $\mathrm{k}_{\mathrm{t} 3}$ are tire stiffness coefficients and $\mathrm{C}_{\mathrm{s} 1}$ and $\mathrm{C}_{\mathrm{s} 2}$ are suspension damping coefficients and $\mathrm{f}_{\mathrm{d}}$ is the nonlinear damping force described in Equation(1). $\mathrm{k}_{\mathrm{s} 2}$ and $\mathrm{k}_{\mathrm{s} 3}, \mathrm{k}_{\mathrm{t} 2}$ and $\mathrm{k}_{\mathrm{t} 3}$ and $\mathrm{C}_{\mathrm{s} 3}$ are the stiffness and damper nonlinear responses at higher loads.

Equations (2-3) are the non-linear equations obtained from Fig. 2 using Newton's second law of motion. Here the non-linearity is considered in the suspension and tire stiffness by modeling it as third order polynomial function and in suspension damper by modeling it as second order polynomial function Sawant and Tamboli [14].

\section{SIMULATION}

The simulation results for the nonlinear semi-active suspension system are obtained using Matlab/Simulink. The Simulink model for the linear and nonlinear semiactive systems are illustrated in Figs. 3-4 respectively.

The Simulink model shown in Fig. 3 is based on the linear mathematical equations. The constant parameters i.e. $\mathrm{m}_{\mathrm{s}}$, $\mathrm{m}_{\mathrm{u}}, \mathrm{k}_{\mathrm{s}}, \mathrm{k}_{\mathrm{t}}$ and $\mathrm{C}_{\mathrm{s}}$ of the model are represented by the gain blocks in the Simulink model. Sprung mass and unsprung mass displacements are obtained by using the integration block.

Similarly, the Simulink model for the non-linear semi-active suspension system is developed based on Equations (2$3)$. For the step input, signal builder block is used while for sinusoidal input Matlab function block is used which calls a Matlab function script file.

The values of various parameters for the nonlinear semiactive suspension system are given in Table 1 as described by Sawant and Tamboli [14] and Muresan [15]. 
The values of parameters for Bingham model for different current inputs obtained from Felix-Herran et. al. [16] Modeling and Control for a semi-active suspension with Magneto Rheological Damper Including the Actuator Dynamics, Septmber 30, 2008-October 3, 2008) are given in Table 2.

\section{VALIDATION}

Validation of the linear model is performed by analytical method. First of all, the transfer function is determined by taking Laplace transform of the dynamic equations of the system with zero initial conditions. Then the solution of the system is determined for a unit step response by using Matlab. The Laplace transforms equations are given in Equations (4-5).

$\left(m_{s} S^{2}+C_{s} S+k_{s}\right) X_{s}+F_{m r}=\left(C_{s} S+k_{s}\right) X_{u}$

TABLE 1. SUSPENSION COEFFICIENTS VALUES

\begin{tabular}{|c|c|c|c|}
\hline Quantity & Value & Quantity & Value \\
\hline $\mathrm{M}_{\mathrm{s}}$ & $240 \mathrm{~kg}$ & $\mathrm{~K}_{\mathrm{t} 1}$ & $5501.612 \mathrm{~N} / \mathrm{m}$ \\
\hline $\mathrm{M}_{\mathrm{u}}$ & $36 \mathrm{~kg}$ & $\mathrm{~K}_{\mathrm{t} 2}$ & $520.3612 \mathrm{~N} / \mathrm{m}^{2}$ \\
\hline $\mathrm{K}_{\mathrm{s} 1}$ & $12394 \mathrm{~N} / \mathrm{m}$ & $\mathrm{K}_{\mathrm{t} 3}$ & $-19.12 \mathrm{~N} / \mathrm{m}^{3}$ \\
\hline \multirow{2}{*}{$\mathrm{K}_{\mathrm{s} 2}$} & $-73696 \mathrm{~N} / \mathrm{m}^{2}$ & $\mathrm{C}_{\mathrm{s} 1}$ & $1385.4 \mathrm{~N}-\mathrm{s} / \mathrm{m}$ \\
\cline { 2 - 4 } & $3170400 \mathrm{~N} / \mathrm{m}^{3}$ & $\mathrm{C}_{\mathrm{s} 2}$ & $524.28 \mathrm{~N}-\mathrm{s}^{2} / \mathrm{m}^{2}$ \\
\hline
\end{tabular}

TABLE 2. BINGHAM MODEL PARAMETERS

\begin{tabular}{|c|c|c|c|}
\hline Currents & \multicolumn{3}{|c|}{ Values of Parameters } \\
\hline I (A) & $\mathrm{f}_{\mathrm{c}}(\mathrm{N})$ & $\mathrm{C}_{\mathrm{o}}(\mathrm{N}-\mathrm{s} / \mathrm{m})$ & $\mathrm{f}_{\mathrm{o}}(\mathrm{N})$ \\
\hline 0.0 & 43.95 & 735.90 & 195.51 \\
\hline 0.4 & 262.13 & 3948.70 & 186.28 \\
\hline
\end{tabular}

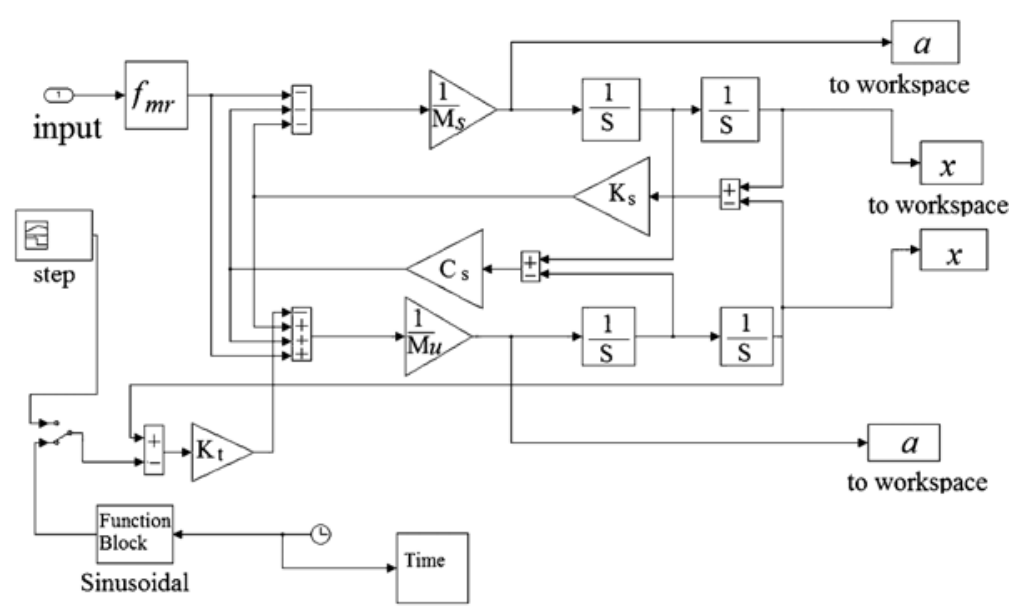

FIG. 3. SIMULINK MODEL FOR LINEAR SEMI-ACTIVE SUSPENSION SYSTEM

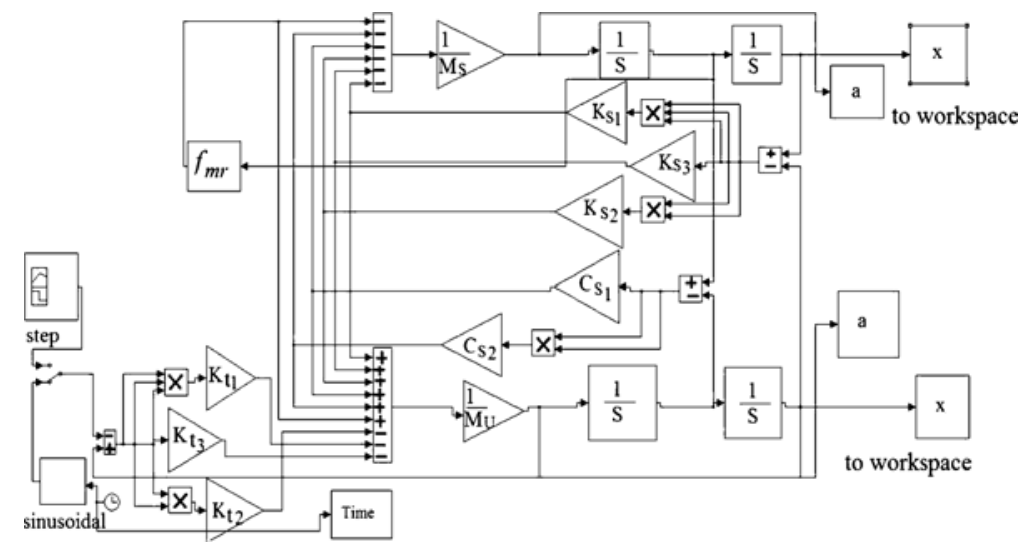

FIG. 4. SIMULINK MODEL FOR NON-LINEAR SEMI-ACTIVE SUSPENSION SYSTEM 
$\left(C_{s} S+k_{s}\right) X_{s}+F_{m r}=\left(m_{u} S^{2}+C_{s} S+k_{s}+k_{t}\right) X_{u}$

The suspension displacement obtained through Laplace transform is given by Equation (6).

$\mathrm{x}_{\mathrm{s}}=\frac{\left(\mathrm{c}_{\mathrm{s}} \mathrm{k}_{\mathrm{t}} \mathrm{s}+\mathrm{k}_{\mathrm{s}} \mathrm{k}_{\mathrm{t}}\right) \mathrm{x}_{\mathrm{t}}-\left(\mathrm{m}_{\mathrm{u}} \mathrm{s}^{2}+\mathrm{k}_{\mathrm{t}}\right) \mathrm{F}_{\mathrm{mr}}}{\mathrm{m}_{\mathrm{s}} \mathrm{m}_{\mathrm{u}} \mathrm{s}^{4}+\left(\mathrm{m}_{\mathrm{u}} \mathrm{c}_{\mathrm{s}}+\mathrm{m}_{\mathrm{s}} \mathrm{c}_{\mathrm{s}}\right)^{3}+\left(\mathrm{m}_{\mathrm{u}} \mathrm{k}_{\mathrm{s}}+\mathrm{m}_{\mathrm{s}} \mathrm{k}_{\mathrm{s}}+\mathrm{m}_{\mathrm{s}} \mathrm{k}_{\mathrm{t}}\right) \mathrm{s}^{2}+\left(\mathrm{c}_{\mathrm{s}} \mathrm{k}_{\mathrm{t}}-\mathrm{c}_{\mathrm{s}} \mathrm{k}_{\mathrm{s}}\right) \mathrm{s}+\mathrm{k}_{\mathrm{t}} \mathrm{k}_{\mathrm{s}}}$

Equation (6) is obtained from the Equations (4-5) by solving it for suspension displacement, $\mathrm{x}_{\mathrm{s}}$.

The suspension displacement response obtained through analytical method is shown in Fig. 5 which is very similar to the Simulink model suspension displacement shown in Fig. 6.

\section{SIMULATION RESULTS}

For analysis of the nonlinear system, the Simulink model of Fig. 3 is used. A step and a sinusoidal road disturbance is used for system excitation to study its response for a variety of road profiles.

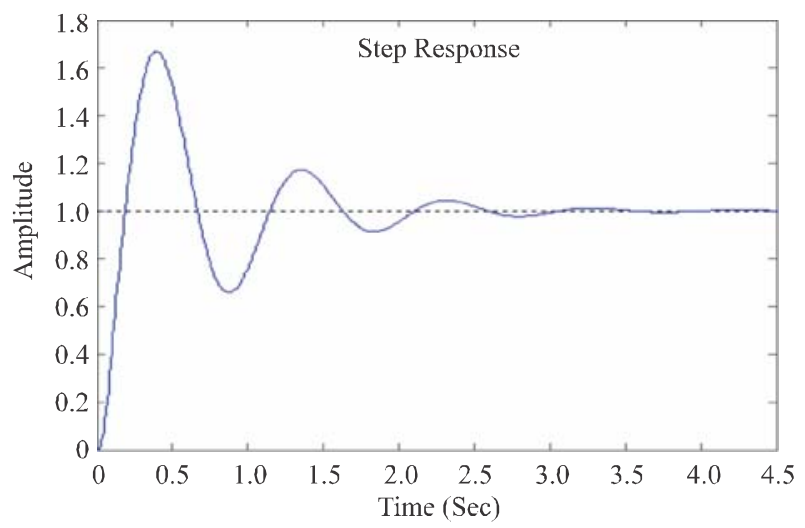

FIG. 5. ANALYTICAL SOLUTION SUSPENSION DISPLACEMENT

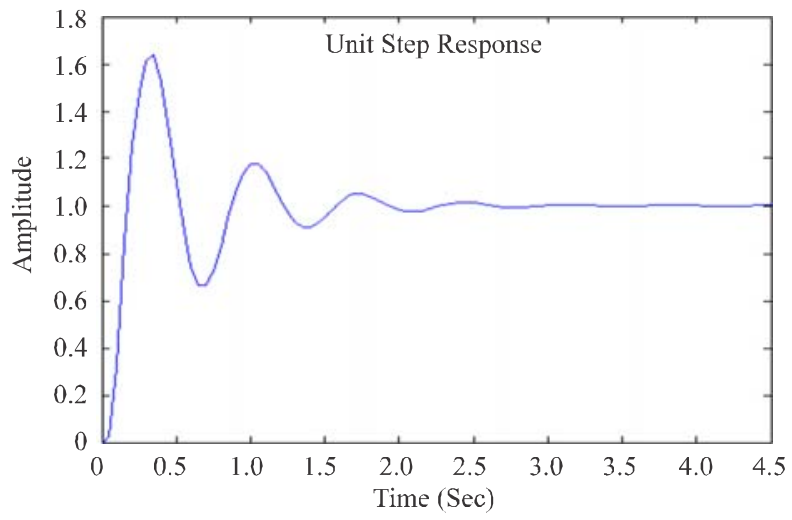

FIG. 6. SIMULINK SUSPENSION DISPLACEMENT RESPONSE
A step input shown in Fig. 7 and a double cosine road bumpgivenis shown in Fig. 8.

$x_{t}=\frac{a}{2}\{1-\cos (2 \pi t)\}$

where a is the amplitude of the sine wave.

$x_{t}=\left\{\begin{array}{cc}0.07 & 0.75 \leq t \leq 1 \\ 0.06 & 10 \leq t \leq 10.25 \\ 0 & \text { Otherwise }\end{array}\right.$

The comparison is based on the sprung mass and unsprung mass displacement of the semi-active suspension system. Sprung mass displacements for both linear and non-linear system for sinusoidal road disturbance are shown in Fig. 9. Unsprung mass displacement for both linear and non-linear system for sinusoidal road disturbance are shown in Fig. 10. Sprung mass displacements for both linear and non-linear system for step input are shown in Fig. 11. Unsprung mass displacements for linear and non-linear system for step input are shown in Fig. 12.
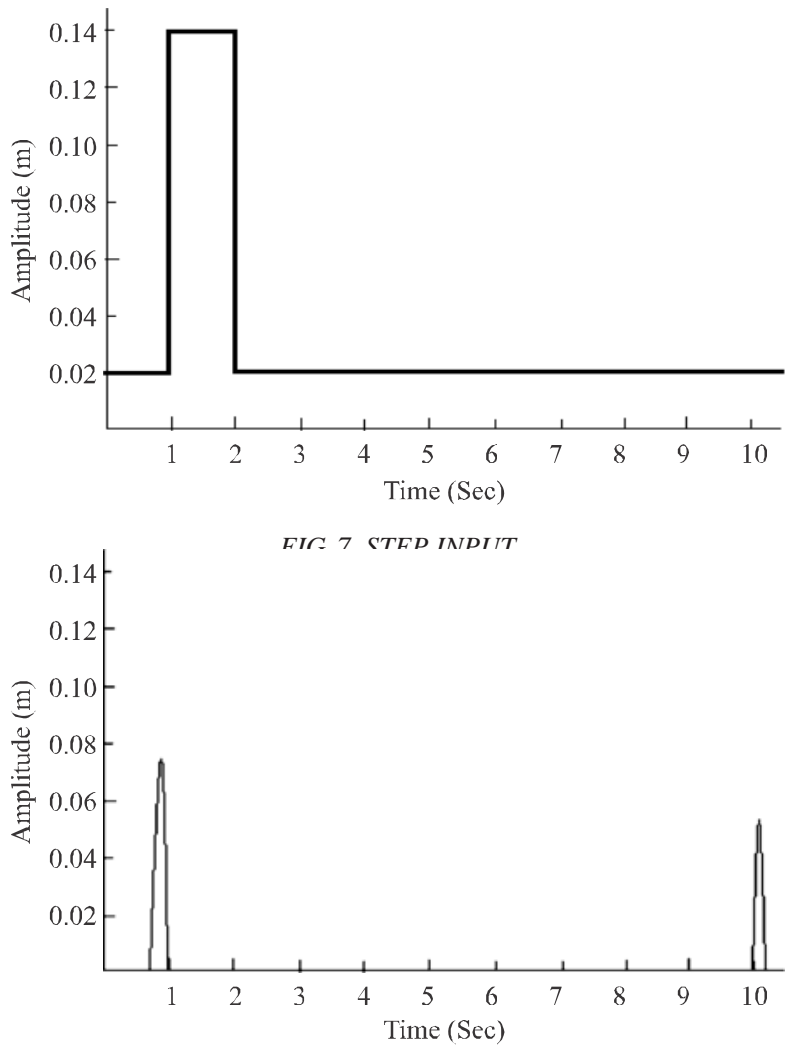

FIG. 8. SINUSOIDAL INPUT

Mehran University Research Journal of Engineering \& Technology, Volume 37, No. 2, April, 2018 [p-ISSN: 0254-7821, e-ISSN: 2413-7219] 


\section{RESULTS AND DISCUSSION}

It is obvious from the transient response of the suspension system that a difference between linear and non-linear system does exists. This difference is based on the settling time, maximum overshoot and steady state error. The reference displacement is steady state response of the linear system. The performance of both types of the systems were studied on 20 seconds scale.

For sinusoidal road input of Figs. 9-10, the difference between the linear and non-linear system for the sprung and unsprung mass displacement based on different parameters are tabulated in Table 3.

Table 3 shows that maximum displacements for the linear system are greater than the non-linear system. The settling time for the sprung mass displacement of the

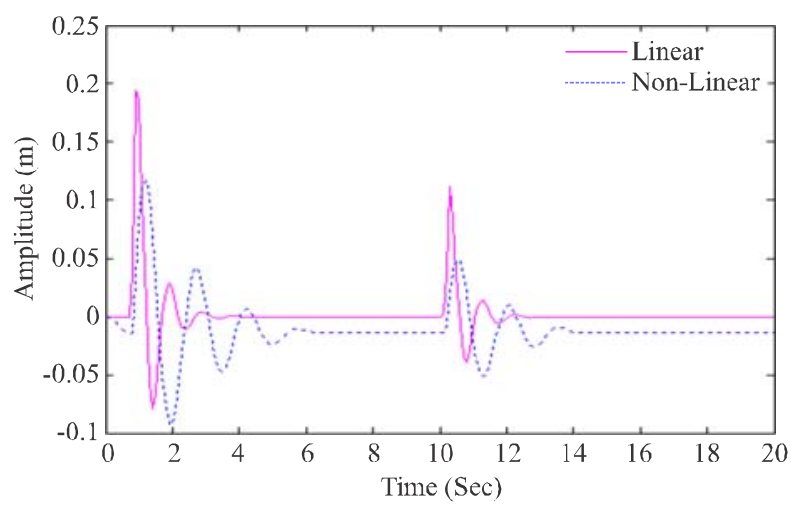

FIG. 9. SPRUNG MASS DISPLACEMENT FOR LINEAR AND NONLINEAR SYSTEM

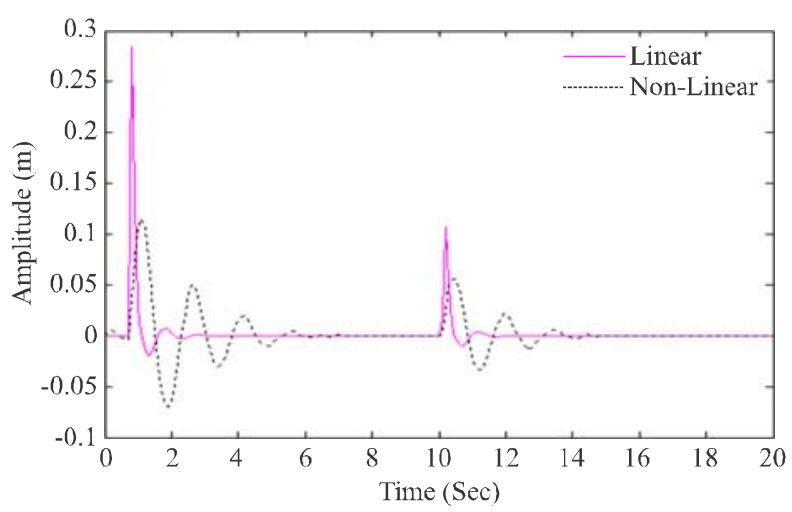

FIG. 10. UNSPRUNG MASS DISPLACEMENT FOR LINEAR AND NON-LINEAR SYSTEM linear system is $12.5 \%$ whereas the settling time for the sprung mass displacement of the non-linear system is $25 \%$. The settling time for the unsprung mass displacement of the linear system is $11 \%$ whereas the settling time for the unsprung mass displacement of the non-linear system is $26 \%$.

For step input of Figs. 11-12, the difference between the linear and non-linear system for the sprung and unsprung mass displacement based on different parameters are tabulated in Table 4.

Table 4 shows that maximum displacement of sprung mass and unsprung mass for the linear system is smaller than the non-linear system. Settling time for the sprung mass of the linear system is $15 \%$ while for non-linear system it is $50.1 \%$. Similarly settling time for the sprung mass of the linear system is $16 \%$ while for non-linear system it is $50 \%$.

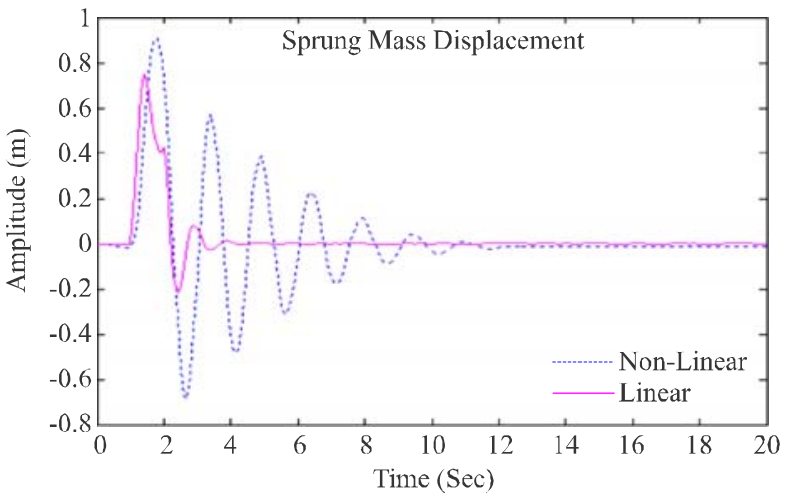

FIG. 11. SPRUNG MASS DISPLACEMENT FOR STEP INPUT

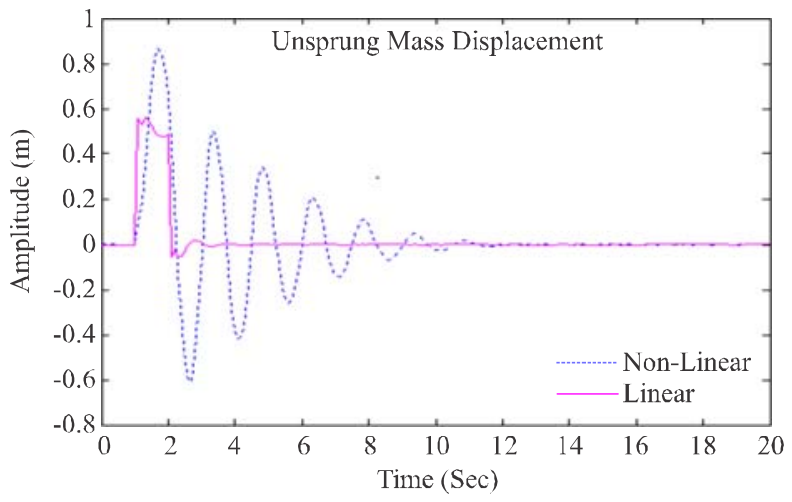

FIG. 12. UNSPRUNG MASS DISPLACEMENT FOR STEP INPUT 
TABLE 3. TRANSIENT RESPONSE FOR SINUSOIDAL INPUT

\begin{tabular}{|c|c|c|c|c|}
\hline \multirow{2}{*}{ SinusoidalInput } & System & $\begin{array}{c}\text { MaximumDisplacement } \\
(\mathrm{m})\end{array}$ & $\begin{array}{c}\text { Settling Time } \\
(\mathrm{sec})\end{array}$ & Steady State Error \\
\hline \multirow{3}{*}{ Sprung Mass } & Linear & 0.190 & 2.6 & 0.0 \\
\cline { 2 - 5 } & Non-Linear & 0.135 & 5.5 & 0.01 \\
\hline \multirow{2}{*}{ UnsprungMass } & Linear & 0.290 & 2.2 & 0.0 \\
\cline { 2 - 5 } & Non-Linear & 0.115 & 5.6 & 0.0 \\
\hline
\end{tabular}

TABLE 4. TRANSIENT RESPONSE FOR STEP INPUT

\begin{tabular}{|c|c|c|c|c|}
\hline \multirow{2}{*}{ Step Input } & System & $\begin{array}{c}\text { MaximumDisplacement } \\
(\mathrm{m})\end{array}$ & $\begin{array}{c}\text { Settling Time } \\
(\mathrm{sec})\end{array}$ & Steady State Error \\
\hline \multirow{3}{*}{ Sprung Mass } & Linear & 0.77 & 3.1 & 0.0 \\
\cline { 2 - 5 } & Non-Linear & 0.92 & 10.1 & 0.001 \\
\hline \multirow{2}{*}{ UnsprungMass } & Linear & 0.56 & 3.2 & 0.0 \\
\cline { 2 - 5 } & Non-Linear & 0.89 & 10.0 & 0.0 \\
\hline
\end{tabular}

\section{CONCLUSION}

Comparing the tabulated results of the above tables, a considerable difference has been observed in the sprung and unsprung mass displacements and accelerations. The graphs of the non-linear system deviate from the graph of the linear system. Maximum value of settling time for the displacements and accelerations has been observed due to non-linear behavior of basic components. Maximum amplitudes of displacement and acceleration for the linear systemis also different from the non-linear systems.

Therefore, it is necessary to include non-linearity in modeling the dynamic response of the vehicle suspension system.

\section{ACKNOWLEDGEMENT}

The authors whish to express this gratitude to Prof. Dr. Tahir Khan, University of Engineering \& Technology, Peshawar, Pakistan, for his cooperation and valuable support in the culminations of this research work

\section{REFERENCES}

[1] Rao, T.M, Rao, G.V., Rao, K.S., and Purushottam, A., "Analysis of Passive and Semi Active Controlled Suspension Systems for Ride Comfort in an Omnibus Passing over a Speed Bump", International Journal of Research and Review in Applied Sciences, Volume 5, No. 1, pp. 1-11, October, 2010 .

[2] Aldair A.A., "Neurofuzzy Controller Based Full Vehicle Nonlinear Active Suspension Systems",Ph.D. Thesis, University of Sussex, pp. 1-294, Brighton, UK, March, 2012.

[3] Khajavi, M.N., and Abdollahi, V., "Comparison between Optimized Passive Vehicle Suspension System and Semi Active Fuzzy Logic Controlled Suspension System Regarding Ride and Handling", International Journal of Mechanical, Aerospace, Industrial and Mechatronics Engineering, Volume 1, No. 1, pp. 1-5, 2007.

[4] Carter A.K., "Transient Motion Control of Passive and Semiactive Damping for Vehicle Suspensions, Blaksburg", Master Thesis, Virginia Polytechnic Institute and State University, pp. 1-106, Virginia, July, 1998.

[5] Pekgokgoz, R.K., Gurel, M., Bilgehan, A.M., and Kisa, M., "Active Suspension of Cars using Fuzzy Logic Controller Optimized by Genetic Algorithm", International Journal of Engineering and Applied Sciences, Volume 2, No. 4, pp. 27-37, July, 2010. 
[6] Sawant, S.H., “Analysis and Comparison of Vehicle Dynamic System with Nonlinear Parameters Subjected to Actual Random Road Excitations", International Journal of Mechanical Engineering and Technology, Volume 3, No. 2, pp. 284-299, August, 2012.

[7] Lajqi S., and Pehan, S., "Design and Optimizations of Active and Semi-Active Non-Linear Suspension Systems for a Terrain Vehicle", Journal of Mechanical Engineering, Volume 12, No. 58, pp. 732-743, August, 2012.

[8] Hingane, A.A., Sawant, S.H., Chavan, S., and Shah, A.P., "Analysis of Semi Active Suspension System with Bingham Model Subjected to Random Road Excitation Using MATLAB/Simulink", $2^{\text {nd }}$ International Conference on Emerging Trends in Engineering, Jaysigpur, India, 2013.

Qazi, A.J., Khan, A., Khan, M., Tand, N.S., "Parametric Analysis of Various Control Algorithms for Semi-Active Suspension System", Journal of Engineering and Applied Sciences, Volume 31, No. 2, pp. 89-97, June, 2012.
Kong, L., Zhao, X., and Qi, B., "Study on Semi-Active Suspension System of Tracked Vehicle Based on Variable Universe Fuzzy Control”, International Conference on Mechatronics and Automation, Beijing, China, 2011.

[13] Chavan, S.P., Sawant, S.H., and Tamboli, J.A., "Experimental Verification of Passive Quarter Car Vehicle Dynamic System Subjected to Hormonic Road Excitation with Nonlinear Parameters", IOSR Journal of Mechanical and Civil Engineering, Jaysingpur, India, 2013.

[14] Sawant, S.H., and Tamboli, J.A., "Comparative Study of Passive and Semi-Active Suspension System Subjected to Random Excitation", International Journal of Mechanical and Automobile Engineering, Volume 21, No. 1, pp. 01-06, March, 2012.

Abu-Khudhair Muresan, A.R., and Yang, S.X., "Fuzzy Control of Semi-Active Automotive Suspensions", International Conference on Mechatronics and Automation, Changchun, China, August, 2009.

[16] Felix-Herran L.C., Rodrigues-Ortiz J.D., Jand RamirezMendoza, R., "Modeling and Control for a Semi-Active Suspension with Magneto Rheological Damper Including the Actuator Dynamics", Electronics, Robotics and Automotive Mechanics Conference, Cuernavaca, Morelos, Mexico, September 30, 2008-October 3, 2008. 